\title{
Exogenous Leukemia Inhibitory Factor Stimulates Oligodendrocyte Progenitor Cell Proliferation and Enhances Hippocampal Remyelination
}

\author{
Benjamin E. Deverman and Paul H. Patterson \\ Division of Biology, California Institute of Technology, Pasadena, California 91125
}

New CNS neurons and glia are generated throughout adulthood from endogenous neural stem and progenitor cells. These progenitors can respond to injury, but their ability to proliferate, migrate, differentiate, and survive is usually insufficient to replace lost cells and restore normal function. Potentiating the progenitor response with exogenous factors is an attractive strategy for the treatment of nervous system injuries and neurodegenerative and demyelinating disorders. Previously, we reported that delivery of leukemia inhibitory factor (LIF) to the CNS stimulates the self-renewal of neural stem cells and the proliferation of parenchymal glial progenitors. Here we identify these parenchymal glia as oligodendrocyte $(\mathrm{OL})$ progenitor cells $(\mathrm{OPCs})$ and show that LIF delivery stimulates their proliferation through the activation of gp130 receptor signaling within these cells. Importantly, this effect of LIF on OPC proliferation can be harnessed to enhance the generation of OLs that express myelin proteins and reform nodes of Ranvier in the context of chronic demyelination in the adult mouse hippocampus. Our findings, considered together with the known beneficial effects of LIF on OL and neuron survival, suggest that LIF has both reparative and protective activities that make it a promising potential therapy for CNS demyelinating disorders and injuries.

\section{Introduction}

Oligodendrocytes (OLs) wrap axons in myelin, coordinate ion channel clustering at nodes of Ranvier, and provide trophic support for axons. Consequently, the OL loss that occurs in the lesions of demyelinating disorders such as multiple sclerosis (MS) and after traumatic CNS injury contributes to ongoing disability. Remyelination of these lesions by endogenous OL progenitor cells (OPCs) occurs in animal models and some patients but is variable and insufficient. One approach to enhance remyelination is to administer factors that can mobilize endogenous OPCs and neural stem cells (NSCs) and direct their differentiation into OLs. In this regard, several of the neuropoietic, gp130 cytokines, most notably leukemia inhibitory factor (LIF) and ciliary neurotrophic factor (CNTF), have multiple activities that make them attractive therapeutic candidates. First, in culture, LIF and CNTF enhance the proliferation of OPCs (Barres et al., 1996). Second,

Received July 25, 2011; revised Dec. 1, 2011; accepted Dec. 16, 2011.

Author contributions: B.E.D. and P.H.P. designed research; B.E.D. performed research; B.E.D. and P.H.P. analyzed data; B.E.D. and P.H.P. wrote the paper.

The authors declare no competing financial interests.

This work was supported by a fellowship to B.E.D. from the California Institute for Regenerative Medicine and by grants from the National Institute of Neurological Disorders and Stroke (NS045744 and ARRANS45744) and the McGrath Foundation. We thank Sylvian Bauer for thoughtful discussions and assistance initiating this study; Tania Banerji for technical assistance; Elaine Hsiao, Jan Ko, Natalia Malkova, and Puja Saluja for critical reading of this manuscript; and members of the California Institute of Technology Office of Laboratory Animal Resources, especially N. Miyamoto, for consistent excellent animal care. We also thank W. Muller and W. Richardson for the generous gifts of transgenic mouse lines.

Correspondence should be addressed to Paul H. Patterson, Division of Biology M/C 216-76, California Institute of Technology, Pasadena, CA 91125. E-mail: php@caltech.edu.

DOI:10.1523/JNEUROSCI.3803-11.2012

Copyright $\odot 2012$ the authors $\quad 0270-6474 / 12 / 322100-10 \$ 15.00 / 0$
LIF and CNTF promote the maturation of cultured OPCs into OLs (Mayer et al., 1994), and in mixed hippocampal cultures, the release of LIF by astrocytes stimulates myelination (Ishibashi et al., 2006). Third, after injury, LIF activates astrocytes and microglia (Sugiura et al., 2000; Kerr and Patterson, 2004), cell types that can modulate disease by limiting the spread of the lesion and clearing myelin debris, respectively, and produce cytokines and growth factors critical for remyelination (Arnett et al., 2001; Mason et al., 2001; Hendriks et al., 2008; Haroon et al., 2011). Fourth, axon regrowth after optic nerve crush is enhanced by inflammation through a process that requires CNTF and LIF (Leibinger et al., 2009). Fifth, LIF stimulates the self-renewal of adult NSCs in the subventricular zone (SVZ), which may expand this population to facilitate repair (Bauer and Patterson, 2006). This finding has relevance for the repair of demyelination since NSCs can generate migratory OPCs that differentiate into OLs and contribute to remyelination (Menn et al., 2006). Finally, several gp130 cytokines also enhance the survival of OLs in culture (Louis et al., 1993; Mayer et al., 1994; Barres et al., 1996; Zhang et al., 2006) and in models of spinal cord injury and MS (Butzkueven et al., 2002; Kerr et al., 2005; Marriott et al., 2008).

Whereas the protective effects of LIF on OLs are well described, it is not clear that LIF delivery can enhance the endogenous remyelination response. Since LIF not only stimulates OPC proliferation and OL generation in vitro, but also acts on microglia and astrocytes, we hypothesized that supplying exogenous LIF could provide the necessary signals to expand the population of OPCs in demyelinated lesions and promote their differentiation into myelinating OLs. To test this hypothesis, we chose to use the cuprizone model of demyelination in a proof-of-concept ex- 
periment. Cuprizone induces a time course of demyelination and remyelination that is well characterized and reproducible in regional impact and severity, and it allows for testing potential remyelination-promoting paradigms at times when OLs have been almost completely ablated. This provides for a clear interpretation of the mechanism underlying any observed therapeutic benefit (i.e., that it is attributable to enhanced remyelination rather than protection of existing OLs), a distinction that is critical for evaluating the potential remyelination-promoting effects of LIF and dissociating these effects from its pro-survival effects on OLs.

\section{Materials and Methods}

Animals. C57BL/6J, Rosa-YFP (Srinivas et al., 2001), and Ng2-Cre BAC (Zhu et al., 2008) transgenic mice were obtained from The Jackson Laboratory. The gp $130^{\mathrm{fl}}$ mice (Betz et al., 1998) and PDGFR $\alpha$-CreER BAC transgenic mice (Rivers et al., 2008) were generous gifts from W. Muller (University of Manchester, Manchester, UK) and W. Richardson (Wolfson Institute for Biomedical Research, University College London, London, UK), respectively. The gp $130^{\mathrm{fl}}$; $\mathrm{Ng} 2$-Cre and PDGFR $\alpha$-CreER;Rosa-YFP mice were on mixed backgrounds: $\mathrm{C} 57 \mathrm{BL} / 6$; FVB and CBA;C57BL/6, respectively. Littermates, both male and female, were used for all studies in genetically modified mice. Primer sequences for genotyping are available on request. All procedures were approved by the California Institute of Technology Institutional Animal Care and Use Committee.

Adenovirus injection. Recombinant adenovirus, $\sim 2.7 \times 10^{6} \mathrm{pfu}$ in $3 \mu \mathrm{l}$ (Zhu et al., 2001), encoding mouse LIF (Ad-LIF) or LacZ (Ad-LacZ) was injected into the lateral ventricle as described (Bauer and Patterson, 2006). This method primarily infects ependymal cells (Doetsch et al., 1999; Bauer and Patterson, 2006). Five to six mice were used per virusinjected group for cuprizone experiments, and two to three mice were used per group for Ad-LIF-induced proliferation assays.

Bromodeoxyuridine and tamoxifen administration. Bromodeoxyuridine (BrdU; Sigma-Aldrich) for injection was made at $10 \mathrm{mg} / \mathrm{ml}$ in $0.9 \%$ $\mathrm{NaCl}$ and sterile filtered. Mice were given intraperitoneal injections of 50 $\mathrm{mg} / \mathrm{kg} \mathrm{BrdU}$ at the indicated times before they were killed. For long-term BrdU labeling, BrdU was dissolved in $\mathrm{H}_{2} \mathrm{O}$ at a concentration of 0.8 $\mathrm{mg} / \mathrm{ml}$, sterile filtered, aliquoted, and stored at $-20^{\circ} \mathrm{C}$. Water containing BrdU was changed daily. Tamoxifen was dissolved by sonication in sunflower oil. Mice were given $4 \mathrm{mg}$ of tamoxifen by a single daily intraperitoneal injection for 3 consecutive days.

Cuprizone treatment. Eight-week-old C57BL/6J mice from The Jackson Laboratory were fed a diet containing $0.2 \%$ cuprizone (SigmaAldrich), which was freshly prepared and mixed into milled chow (5001 Rodent Diet; Lab Diet) three times per week. After cuprizone treatment, mice were returned to a standard pellet chow.

Tissue processing and immunostaining. Mice were anesthetized with Nembutal and transcardially perfused first with $0.1 \mathrm{M}$ phosphate buffer (PB), pH 7.4 (room temperature) and then with freshly prepared $4 \%$ paraformaldehyde in $\mathrm{PB}\left(4^{\circ} \mathrm{C}\right)$. Brains were postfixed for $4-5 \mathrm{~h}$ for cryostat sectioning (cuprizone experiments) or overnight for vibratome sectioning (experiments in Fig. $1 E-H, 4$ ). For cryostat sectioning, brains were placed in $4^{\circ} \mathrm{C} \mathrm{PB}$ overnight followed by $24 \mathrm{~h}$ of immersion in $20 \%$ sucrose in PB. The brains were then frozen in OCT (Sakura TissueTek) and stored at $-80^{\circ} \mathrm{C}$ until sectioning. Fourteen-micrometer coronal sections were cut on a cryostat (Leica), dried overnight at room temperature, and stored at $-20^{\circ} \mathrm{C}$. Floating coronal vibratome sections were cut at $50 \mu \mathrm{m}$, collected in PB containing $0.02 \%$ sodium azide, and stored at $4^{\circ} \mathrm{C}$.

Immunostaining was performed by diluting primary and secondary antibodies in PBS containing $10 \%$ goat or donkey serum and $0.1 \%$ Triton $\mathrm{X}-100$ (frozen sections) or $0.5 \%$ Triton X-100 (floating sections). Primary antibodies used were rat anti-BrdU* (1:250; Oxford Biotechnology or Abcam), mouse anti-CC1 (1:200; Calbiochem), rabbit anti-GFAP (1: 1000; Dako), rabbit anti-GFP (1:1000; Invitrogen), chicken anti-GFP (1:2000; Abcam), rabbit anti-Ibal (1:500; Biocare Medical), mouse anti$\mathrm{K}_{\mathrm{V}} 1.2^{*}\left(1: 1000\right.$; NeuromAb), mouse anti-Na $1.6^{*}$ (1:500; Alamone Labs), mouse anti-neurofilament $(\mathrm{NF})^{\star}(1: 50$, clone $2 \mathrm{H} 3$; Developmen- tal Studies Hybridoma Bank), rabbit anti-Ng2 (1:300; Millipore), goat anti-Olig2 (1:500; R \& D Systems), mouse anti-proteolipid protein $(\mathrm{PLP})^{\star}(1: 500$; Millipore), mouse anti-Rip (1:50; Developmental Studies Hybridoma Bank), and rabbit anti-pSTAT3-Y705* (1:500; Cell Signaling Technology). Primary antibody incubations were performed at room temperature overnight (slide-mounted sections) and for $2-3 \mathrm{~d}$ at $4^{\circ} \mathrm{C}$ (floating sections). Several antigens (marked above with an asterisk) required an antigen unmasking pretreatment. For frozen sections, this was performed by incubating slides at $100^{\circ} \mathrm{C}$ for 30 min with a $\mathrm{pH} 6$ unmasking agent (Dako) before proceeding with primary antibody incubation. For floating sections, unmasking the BrdU and pSTAT3 antigens required pretreatment with $0.1 \mathrm{~N} \mathrm{HCl}$ at $4^{\circ} \mathrm{C}$ for 30 min followed by immersion in $2 \mathrm{~N} \mathrm{HCl}$ at $37^{\circ} \mathrm{C}$ for $30 \mathrm{~min}$. Goat or donkey anti-species- and isotype-specific antibodies conjugated to Alexa-488, 568, or 633 (Invitrogen) were incubated with tissue sections for $1-2 \mathrm{~h}$ (frozen sections) or overnight (floating sections). The Rip and NF antibodies were developed by S. Hockfield (Massachusetts Institute of Technology, Cambridge, MA) and T. Jessell (Columbia University, New York, NY), respectively, and were obtained from the Developmental Studies Hybridoma Bank (dshb@uiowa.edu).

Image analysis and quantification. Slide-mounted sections were imaged using a TCS SP confocal microscope (Leica) equipped with argon, krypton, and $\mathrm{He} / \mathrm{Ne}$ lasers. Care was taken to sample sections at similar anatomical levels. For cuprizone studies, cell counts were made from confocal images taken of coronal sections of the medial CC ( -0.6 to 0.8 $\mathrm{mm}$ caudal to bregma) and the dorsal hippocampus $(-1.5$ to $-1.9 \mathrm{~mm}$ caudal to bregma). For the experiment shown in Figure 5, $\mathrm{BrdU}^{+}$cells were counted in images of the fimbria between -0.7 and $+1.6 \mathrm{~mm}$.

PLP and NF staining quantification was performed on $63 \times, 10 \mu \mathrm{m}$ projection images of the $\mathrm{CA} 3$ stratum radiatum (medial to the lateral extent of the mossy fibers) of the hippocampus. A manual threshold, equivalent for all images, was set in ImageJ (http://rsb.info.nih.gov/ij/) for each channel, and the area above that threshold was quantified. The percentage area over threshold for PLP was then divided by the percentage area over threshold for NF and presented as a ratio. All values were normalized to those of the untreated group. Nodes were counted from images of the CA3 stratum radiatum. The number of $\mathrm{Na}_{\mathrm{V}} 1.6^{+}$nodes, flanked on both sides by $\mathrm{Caspr}^{+}$paranodes, was counted in $7 \mu \mathrm{m}$ confocal projections images taken with a $63 \times$ objective. Adobe Photoshop CS3 was used to adjust image contrast and brightness (any adjustments made were made equally for all images within an experiment).

Statistical analysis. Differences between group means were tested for statistical significance using an unpaired, two-tailed Student's t test (two groups) or with a one-way ANOVA and Tukey's multiple comparison test (three or more comparisons). All data are presented as mean \pm SEM. Analyses were performed using Prism $4.0 \mathrm{~b}$ software.

\section{Results}

\section{LIF promotes OPC proliferation in vivo}

In previous work from our group, Bauer et al. (2006) demonstrated that delivery of exogenous LIF using an adenovirus encoding a secreted form of mouse LIF (Ad-LIF) increases the number of proliferating parenchymal glial progenitors expressing Olig2 or S100 threefold to fivefold over the controls that received a $\beta$-galactosidase (LacZ)-encoding virus. Because the primary adult glial progenitor cell population that proliferates outside of the neurogenic niches are Olig2 ${ }^{+}$OPCs (Nishiyama, 2007), this finding suggested that LIF delivery stimulates the proliferation and/or generation of this population. However, whereas Olig2 expression is typically restricted to the OL lineage, it is also expressed by a subset of astrocytes during development and after injury (Cai et al., 2007; Tatsumi et al., 2008), and S100 can be expressed by astrocytes, OPCs, and myelinating OLs (Rickmann, 1995; Hachem et al., 2005). Therefore, we sought to further clarify the identity of the proliferating glia.

Adult OPCs are typically defined and identified by their expression of $\mathrm{Ng} 2$ and platelet-derived growth factor receptor $\alpha$ 

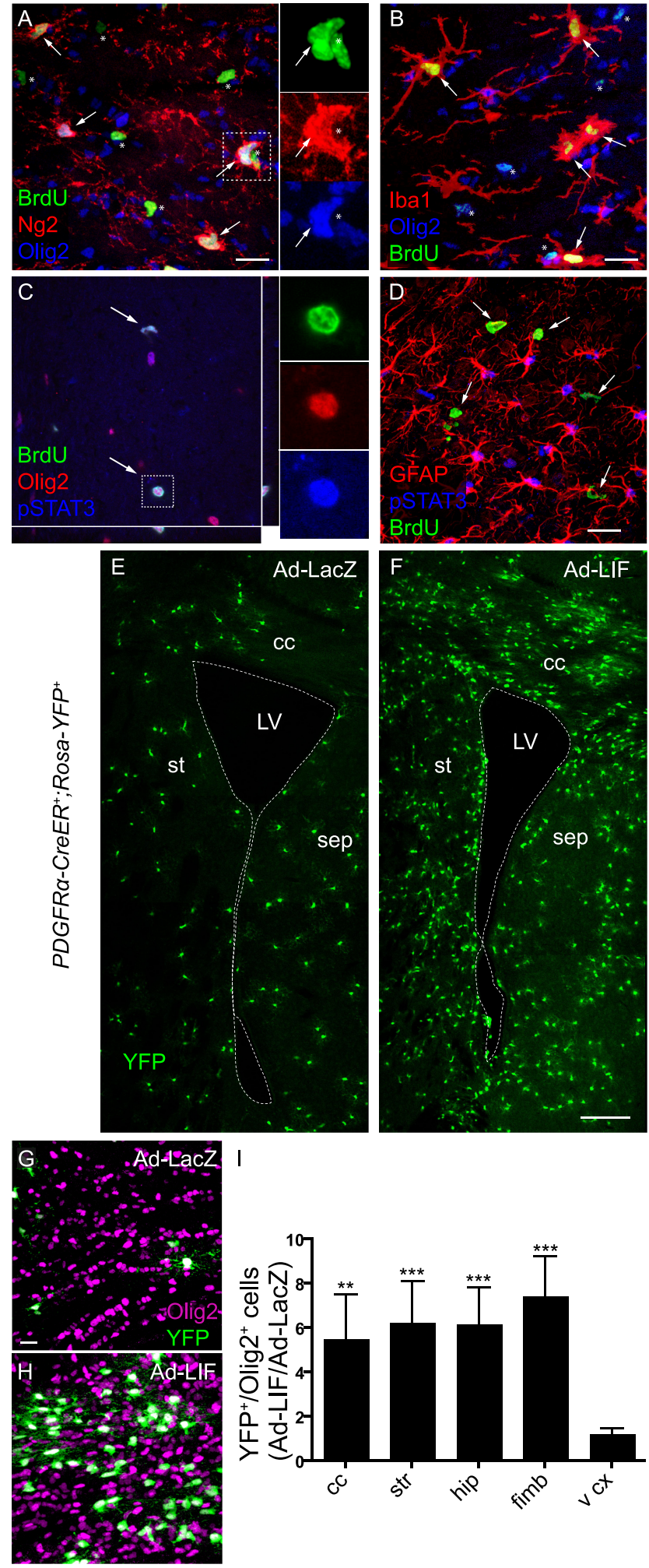

Figure 1. Exogenous LIF stimulates OPC proliferation. To identify cells responding to acute LIF, mice were treated with $\mathrm{Ad}-\mathrm{LIF}$ and given injections of BrdU 3 and $6 \mathrm{~h}$ before they were killed. Images show characterization of BrdU ${ }^{+}$cells (green) by immunostaining. $A$, Many BrdU ${ }^{+}$cells, highlighted by arrows, also display staining for both 0 lig2 (blue) and $\mathrm{Ng2}$ (red). Asterisks highlight $\mathrm{BrdU}^{+}$cells unlabeled by either of these $\mathrm{OPC}$ markers. $\boldsymbol{B}$, Olig2-negative BrdU ${ }^{+}$cells are mostly $\mathrm{lba} 1^{+}$(red) microglia (arrows). C, Ad-LIF treatmentinduces Stat3 activation (phospho-Y705 Stat3-specificimmunostaining; blue) in 0 lig2 ${ }^{+} / \mathrm{BrdU}^{+} \mathrm{OPCs}$ (arrows). The cell highlighted in the dashed box is positive for BrdU (green), Olig2 (red), and pSTAT3 (blue) immunostaining, as can be seen from the enlarged individual channel images shown to the right of the tricolor image. D, LIF induces STAT3 phosphorylation (blue) in $\mathrm{GFAP}^{+}$astrocytes (red), but these cells rarely incorporate BrdU (green) in response to
(PDGFR $\alpha$ ). Three days after intracerebroventricular injection of Ad-LIF, we found that $41.0 \pm 2.7 \%$ (mean $\pm \mathrm{SEM} ; \mathrm{n}=2$ ) of the $\mathrm{BrdU}^{+}$cells proliferating outside of the $\mathrm{SVZ}$ are $\mathrm{Ng}^{+}{ }^{+}$(Fig. $1 A$ ). Nearly all of the proliferating cells not labeled with antibodies directed against $\mathrm{Ng} 2$ or Olig2 are $\mathrm{Ibal}^{+}{ }^{+}$microglia $(55.7 \pm 4.0 \%$ non$\mathrm{SVZ} \mathrm{BrdU}^{+}$cells; mean \pm SEM; $\mathrm{n}=2$ ) (Fig. $1 B$ ), a finding consistent with the previous observation that LIF induces microglial proliferation (Kerr and Patterson, 2004). LIF signaling activates the transcription factor STAT3, and in periventricular areas where STAT3 activation is greatest, we detect activated, phosphorylated STAT3 in $86.5 \pm 2.5 \%$ of the proliferating Olig $2^{+}$OPCs, suggesting that these cells respond directly to LIF (Fig. 1C). Although LIF strongly increases STAT3 activation and GFAP expression in astrocytes, $\mathrm{GFAP}^{+}$cells outside of the SVZ rarely proliferate in response to acute LIF treatment (Fig. 1D). In line with this finding that most of the $\mathrm{BrdU}^{+}$neural parenchymal cells in LIF-treated mice are OPCs and not astrocytes, triple staining for $\mathrm{S} 100$, Olig2, and BrdU confirms that the $\mathrm{BrdU}^{+} / \mathrm{S}_{100^{+}}$and $\mathrm{BrdU}^{+} / \mathrm{Olig} 2^{+}$populations we previously described are nearly completely overlapping (data not shown), suggesting that the subset of $\mathrm{S} 00^{+}$cells that incorporate $\mathrm{BrdU}$ in response to LIF are Olig2 ${ }^{+}$OPCs.

We next asked whether the stimulation of OPC proliferation by LIF expands the pool of OPCs. To test this, we used PDGFR $\alpha$ CreER;ROSA-YFP mice (Rivers et al., 2008), which allow for tamoxifen-inducible cre-dependent expression of the yellow fluorescent protein (YFP) reporter in PDGFR $\alpha^{+}$OPCs and their progeny. YFP expression was induced in OPCs by tamoxifen administration, and mice were given injections of either Ad-LIF or Ad-LacZ. Three weeks later, we found that the population of $\mathrm{YFP}^{+}$cells is dramatically expanded in the periventricular regions of Ad-LIF-treated animals compared with control animals receiving Ad-LacZ (Fig. $1 E-I$ ). The vast majority of the $\mathrm{YFP}^{+}$ cells are Olig2 ${ }^{+}$in both Ad-LIF- and Ad-LacZ-treated mice ( $97.2 \pm 0.4$ and $98.5 \pm 0.6 \%$, respectively, in the dorsal forebrain; $\mathrm{n}=3$ per group; Fig. $1 G, H)$. We observe occasional $\mathrm{YFP}^{+}$cells with neuronal and pericyte morphology, as has been reported after tamoxifen injection in this line (Rivers et al., 2008).

\section{LIF restores OL number after demyelination}

To examine whether exogenous LIF treatment can enhance the generation of OLs after cuprizone-induced demyelination, we treated 8-week-old adult C57BL/6 mice with a cuprizonesupplemented diet for 5 weeks, delivered Ad-LIF or Ad-LacZ by intracerebroventricular injection, and returned the mice to a standard diet. To label cells that proliferate after treatment, we administered $\mathrm{BrdU}$ in the drinking water for a total of $7 \mathrm{~d}$, starting $3 \mathrm{~d}$ after virus injection. Twenty-eight days after ceasing cuprizone treatment and injecting Ad-LIF or Ad-LacZ (18 d after removing BrdU from the drinking water), we assessed the number of newly generated $\mathrm{BrdU}^{+}$OLs with and without LIF treatment (Fig. 2B). Remarkably, compared with controls, LIF increases the number of mature $\mathrm{BrdU}^{+} / \mathrm{CCl}^{+}$OLs in both the

LIF. E-I, Ad-LIF expands the OPC pool. PDGFR $\alpha$-CreER ${ }^{+/-}{ }^{\text {; ROSA-YFP }}{ }^{+/-}$mice were induced with tamoxifen, treated 1 week later with Ad-LacZ $(\boldsymbol{E}, \boldsymbol{G})$ or $\operatorname{Ad-LIF}(\boldsymbol{F}, \boldsymbol{H})$, and killed 3 weeks after adenovirus injection. $\boldsymbol{E}, \boldsymbol{F}$, Immunostaining for the YFP reporter is shown in green. Dotted lines outline the lateral ventricle (LV) walls. cc, Corpus callosum; st, striatum; sep, septum. $\mathbf{G}, \boldsymbol{H}$, Representative images are shown of immunostaining for Olig2 (purple) and YFP (green) in the CC of Ad-LacZ-treated (G) and Ad-LIF-treated (H) mice. Scale bars: $\boldsymbol{A}-\boldsymbol{D}, \boldsymbol{G}, \boldsymbol{H}, 20 \mu \mathrm{m} ; \boldsymbol{E}, \boldsymbol{F}, 200 \mu \mathrm{m}$. $\boldsymbol{I}$ Quantification of the fold increase in YFP ${ }^{+} / 0$ lig2 ${ }^{+}$cells in periventricular regions of the corpus callosum (cc), striatum (str), hippocampus (hip), fimbria (fimb), and ventral cortex ( $v(x) .{ }^{* *} p<0.01$; ${ }^{* * *} p<0.001$. The effect of LIF is not significant in the ventral cortex. 
A
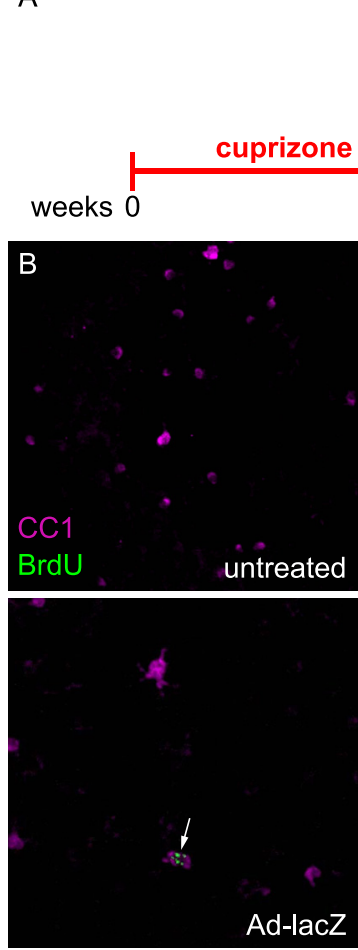

C
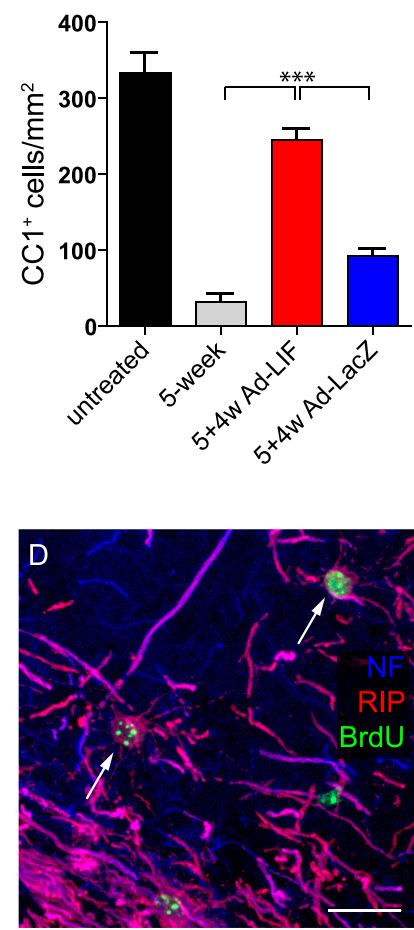

Figure 2. LIF enhances $0 \mathrm{~L}$ generation after acute demyelination. Male C57BL/6 mice were fed cuprizone for 5 weeks, returned to a standard diet, and given an injection of Ad-LIF or Ad-LacZ. Three days after virus injection, BrdU was supplied in the drinking water for $7 \mathrm{~d}$, and newly generated $0 \mathrm{Ls}$ were assessed 4 weeks after virus injection. $A$, A schematic provides an overview of the experimental design. i.c.v. inj., Intracerebroventricular injection. $\boldsymbol{B}$, LIF delivery increases the number of newly generated $\mathrm{BrdU}{ }^{+} / \mathrm{CC}^{+} \mathrm{OLs}$ in the hippocampus compared with Ad-LacZ controls. Representative images are shown of immunostaining of the hippocampi (CA3 region) of mice treated as indicated. $\mathrm{BrdU}^{+}$(green) $/ \mathrm{CC}^{+}$(purple) $0 \mathrm{Ls}$ are highlighted by arrows. Quantification of $\mathrm{BrdU}{ }^{+} / \mathrm{CC}^{+}$cells is provided in the text. C, Quantification of the total number of $\mathrm{CC} 1^{+}$ cells in the CA3 region of the hippocampus. ${ }^{* *} p<0.001$. The difference between the $5+4 w$ Ad-LacZ group and the 5 week group is not significant $(p>0.05)$. D, An example of immunostaining for BrdU (green), the mature 0L protein RIP (red), and axons (NF; blue) is shown for the hippocampus of an Ad-LIF-treated mouse. Scale bars, $20 \mu \mathrm{m}$.

hippocampus and the corpus callosum (CC) by 11.5-fold (105 \pm 6.05 $\mathrm{BrdU}^{+} / \mathrm{CC}^{+}{ }^{+}$cells $/ \mathrm{mm}^{2}$ in LIF-treated animals vs $9.2 \pm 2.6$ in LacZ-treated animals; $p<0.001)$ and 2.5-fold $(491 \pm 57.1$ $\mathrm{BrdU}^{+} / \mathrm{CC}^{+}{ }^{+}$cells $/ \mathrm{mm}^{2}$ in LIF-treated animals vs $196 \pm 62.2 \mathrm{in}$ LacZ-treated animals; $p<0.01$ ), respectively. LIF treatment also increases the percentage of $\mathrm{CC}^{+}{ }^{+}$cells that are $\mathrm{BrdU}^{+}$by 4.6 -fold $(44.4 \pm 3.5 \%$ in LIF-treated animals vs $9.6 \pm 2.4 \%$ in LacZtreated animals; $p<0.001$ ) in the hippocampus and 2.3-fold $(16.5 \pm 1.9 \%$ in LIF-treated animals vs $7.1 \pm 2.1 \%$ in LacZtreated animals; $p=0.01$ ) in the CC. This results in a recovery of $\mathrm{CC}^{+}$OLs in the hippocampus to a level that is significantly greater than that seen in the control, LacZ-treated animals (Fig. $2 C)$. In contrast, the number of $\mathrm{CC}^{+}$OLs in the medial CC, where the spontaneous regeneration of OLs is much greater, is not significantly different between Ad-LIF- and Ad-LacZ-treated animals $\left(2998 \pm 114\right.$ vs $2673 \pm 164 \mathrm{CC}^{+}{ }^{+}$cells $/ \mathrm{mm}^{2}$, respectively; $p>0.05)$. In gray matter (GM) areas such as the hippocampus and cortex, where individual myelinated axons are more easily discernible, we observe $\mathrm{Rip}^{+}$OLs derived from OPCs, which had proliferated early during LIF treatment, making extended contact along axons (Fig. 2D).

These findings demonstrate that LIF dramatically enhances the generation of OLs in both gray matter and white matter tracts after demyelination. Assessing the effect of LIF on remyelination in these mice is, however, complicated by the significant spontaneous remyelination that occurs in the CC and, to a lesser extent, in the hippocampus, after 5 week cuprizone treatment. In contrast to 5-6 week cuprizone treatment, spontaneous remyelination has been reported to be limited after long-term, 12-16 week treatment with cuprizone. The lack of remyelination after long-term cuprizone treatment has been attributed to a reduction in OPCs (Mason et al., 2004) and inhibition by fibroblast growth factor 2 (FGF2) (Armstrong et al., 2002; Armstrong et al., 2006). Therefore, we next tested whether LIF treatment would stimulate OPC proliferation, OL generation, and remyelination under conditions where OL generation and remyelination are otherwise impaired. For this experiment, we treated mice with cuprizone for 12 weeks (Fig. $3 A$ ). Similar to a 5 week course of cuprizone, we found that a 12 week course of cuprizone induces a nearcomplete loss of mature OLs and myelin from the dorsal hippocampus (Fig. $3 E$ and data not shown). We first assessed whether OPCs remaining after 12 weeks of cuprizone treatment still respond to LIF with increased proliferation. Ad-LIF or Ad-LacZ was delivered to mice after a 12 week course of cuprizone, and the mice were returned to their standard diet and allowed to recover for 3 weeks. At the end of this recovery period, we administered BrdU by intraperitoneal injection 2 and $4 \mathrm{~h}$ before the mice were killed to label proliferating cells. The number of proliferating Olig ${ }^{+}$cells is increased by 3.9 -fold over controls after LIF treatment in the hippocampus (Fig. $3 B, C$ ) as is the percentage of Olig ${ }^{+}$cells that are $\mathrm{BrdU}^{+}(3.8 \pm 0.2 \%$ vs $1.3 \pm 0.3 \%$ in Ad-LIF- vs Ad-LacZ-treated animals; $p<0.001)$. A similar trend is observed with LIF treatment in the CC (Fig. 3D), but this does not reach significance. Therefore, even in the context of chronic demyelination, LIF enhances the endogenous progenitor response, at least in the hippocampus where there is less spontaneous OPC proliferation. We next examined whether LIF treatment would promote the generation of mature OLs after long-term demyelination. Indeed, after 3 weeks of recovery, the number of $\mathrm{CCl}^{+} \mathrm{OLs}$ in the hippocampus is increased in LIF-treated mice compared with Ad-LacZtreated mice (Fig. 3E). Remarkably, after 6 weeks of recovery, the number of OLs is restored to near-normal numbers in LIFtreated mice, whereas in stark contrast, little recovery is observed in mice that receive the control LacZ virus (Fig. $3 E$ ). Unlike what we observe in the hippocampus, the number of OLs in the medial $\mathrm{CC}$ recovers to near that seen in untreated mice even in the absence of LIF treatment (Fig. 3F). Thus, the spontaneous OL generation that occurs in the CC obscures any beneficial effect of LIF that may occur in this region.

\section{LIF treatment promotes remyelination}

Based on our encouraging findings in the hippocampus, and our finding that long-term, 12 week cuprizone treatment completely abolishes myelin throughout the dorsal hippocampus, as judged by the loss of PLP immunostaining (Fig. $4 B, I$ ), we next sought to assess the extent of remyelination in the hippocampus. To do this, we performed immunostaining for PLP together with a NF 
A
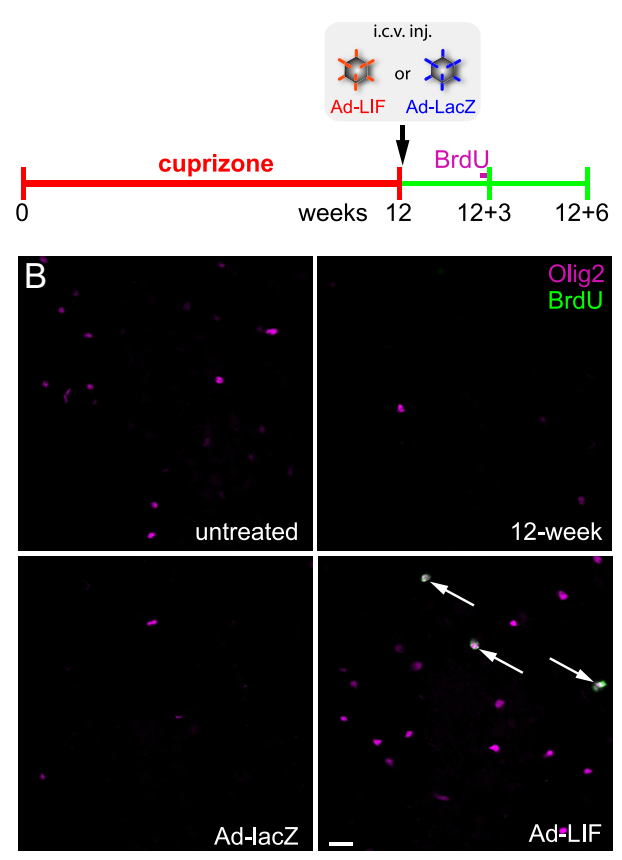

C

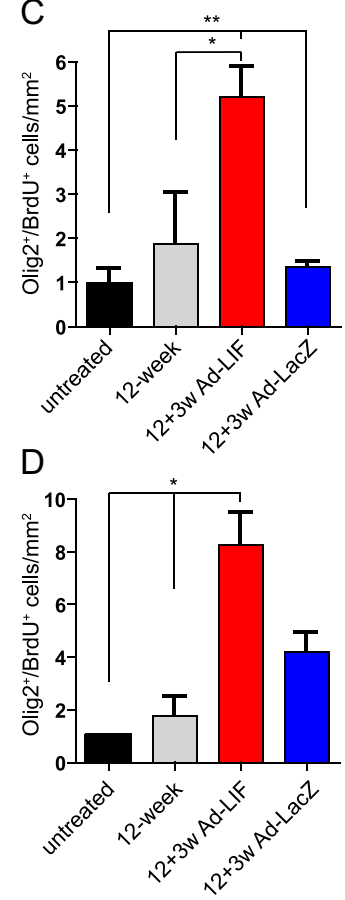

E
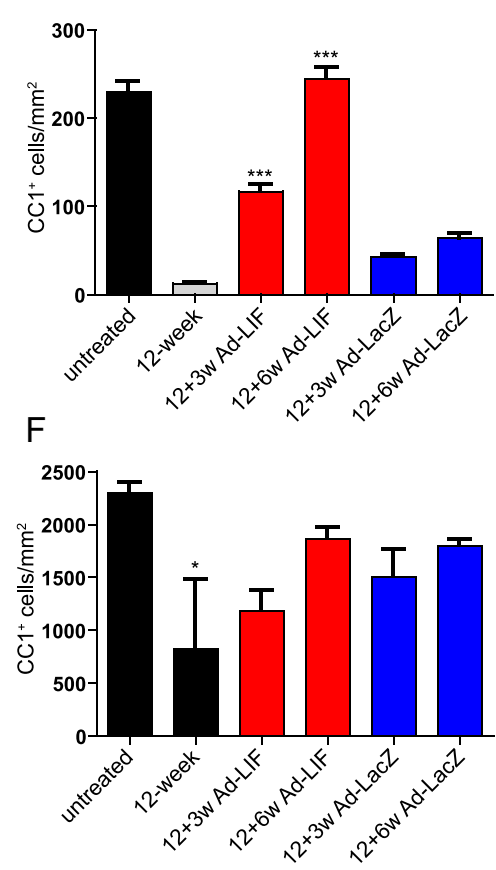

Figure 3. LIF stimulates OPC proliferation and OL generation in the chronically demyelinated hippocampus. Mice were fed cuprizone for 12 weeks, returned to a standard diet, given injections of Ad-LIF or Ad-LacZ, and assessed 3 or 6 weeks later, as indicated. BrdU was injected 2 and $4 \mathrm{~h}$ before the mice were killed. $A$, A schematic provides an overview of the experimental design. i.c.V. inj., Intracerebroventricular injection. $\boldsymbol{B}, \boldsymbol{C}$, LIF increases the number of Olig2 ${ }^{+} / \mathrm{BrdU}^{+}$cells in the hippocampus after 3 weeks of recovery. $\boldsymbol{B}$, Representative images showing immunostaining for 0 lig 2 (purple) and BrdU (green) in the hippocampi of mice treated as indicated. Arrows highlight BrdU ${ }^{+} / 0$ lig2 ${ }^{+}$cells. $C, D$, Quantification of 0 lig2 ${ }^{+} /$BrdU ${ }^{+}$cells in the CA3 region of the hippocampus $(\boldsymbol{C})$ and the medial $C(\boldsymbol{D}){ }^{*} p<0.05 ;{ }^{* *} p<0.01 . \boldsymbol{E}, \boldsymbol{F}$, LIF treatment increases the total number of CC ${ }^{+}$OLs in the demyelinated hippocampus but not the medial CC. Quantification of CC ${ }^{+}$0Ls in the CA3 region of the hippocampus $(\boldsymbol{E})$ and medial CC $(\boldsymbol{F})$. In $\boldsymbol{E}_{\text {, }}{ }^{* * *} p<0.001$ between $12+3$ w Ad-LIF and all other groups and between $12+6$ w Ad-LIF and all groups, other than the untreated group where $p>0.05$. In $\boldsymbol{F},{ }^{*} p<0.05$ between 12 week and untreated and both $12+6$ w groups. Scale bar, $20 \mu \mathrm{m}$.

antibody to label axons. We chose PLP because its expression is restricted to compact myelin, with little to no staining in cell bodies and proximal processes. Because the density of myelinated axons within the hippocampus varies by layer, for consistency we limited our assessment to the stratum radiatum of the CA3 subfield just medial to the unmyelinated mossy fibers (Fig. $4 A-D, I$ ). PLP staining was normalized to NF staining to control for any differences in axon density and minor variations in staining intensities in individual images. Remarkably, after 6 weeks of recovery with Ad-LIF, PLP expression is restored to levels comparable to those observed in mice not treated with cuprizone (Fig. $4 D, I$ ), whereas cuprizone-treated mice given the LacZ virus exhibit little recovery in PLP expression (Fig. 4C,I). LIF treatment also enhances the recovery of PLP expression in the stratum oriens, but interestingly, perforant pathway axons from the entorhinal cortex remyelinate spontaneously, even in the absence of LIF treatment. Likewise, any LIF-dependent myelination of callosal axons that occurred was obscured by spontaneous remyelination (data not shown).

\section{LIF restores the formation of nodes of Ranvier}

Functional recovery of saltatory conductance is dependent on the formation of nodes of Ranvier. To investigate whether the AdLIF-induced enhancement of PLP expression is associated with reformation of nodes of Ranvier, we immunostained for the sodium channel $\mathrm{Na}_{\mathrm{v}} 1.6$, which clusters at nodes, as well as the paranodal protein Caspr and the $\mathrm{K}_{\mathrm{v}} 1.2$ voltage-gated potassium channel subunit, which clusters in juxtaparanodes. In accordance with the complete loss of OLs and myelin protein expression in the hippocampus after cuprizone treatment, the clustering of
$\mathrm{Na}_{\mathrm{v}} 1.6$ channels, $\mathrm{K}_{\mathrm{v}} 1.2$ channels, and the paranodal protein Caspr within axons of the hippocampus is fully disrupted after 12 weeks of cuprizone exposure (Fig. $4 E, F, J$ ). Although scattered nodes return after 6 weeks in Ad-LacZ-injected mice, mice receiving Ad-LIF treatment display a highly significant increase in the number of $\mathrm{Na}_{\mathrm{v}} 1.6^{+}$nodes flanked by Caspr ${ }^{+}$paranodes compared with both 12 week cuprizone- and control Ad-LacZtreated mice (Fig. $4 \mathrm{~F}-H, J$ ). Clustered $\mathrm{K}_{\mathrm{v}} 1.2$ channels can also be detected flanking many, but not all, $\mathrm{Caspr}^{+}$paranodes. Since the accumulation of potassium channels at juxtaparanodes requires compact myelin and not just axon-OL contact (Baba et al., 1999), this also suggests that Ad-LIF treatment restores compact myelin and the potential for saltatory conductance in axons within the stratum radiatum. Therefore, in mice treated with Ad-LIF, newly generated myelinating OLs restore the clustering of axonal sodium and potassium channels as well as axonal-glial paranodal complexes.

We see a similar LIF-induced increase in $\mathrm{PLP}^{+} \mathrm{OL}$ processes and Caspr clustering in the stratum oriens lateral to the CA3 pyramidal cell layer, but, interestingly, in this region, $\mathrm{Na}_{\mathrm{v}} 1.6$ expression is not detectable between many of the paranodes. Caspr clustering is known to be dependent on OL contact and expression of the paranodal OL protein NF155, and we find that NF155 clustering occurs at all sites of axonal Caspr clustering (data not shown). It is not clear whether the lack of $\mathrm{Na}_{\mathrm{v}} 1.6$ channels results from an axo-glial contact on dystrophic axons that fail to cluster $\mathrm{Na}_{\mathrm{v}} 1.6$ channels in response to paranodal junctional formation, or whether the proximity of the lateral stratum oriens to the ventricle and presumably higher LIF concentration drives abnormal axo-glial paranodal junctional complex formation. In sup- 

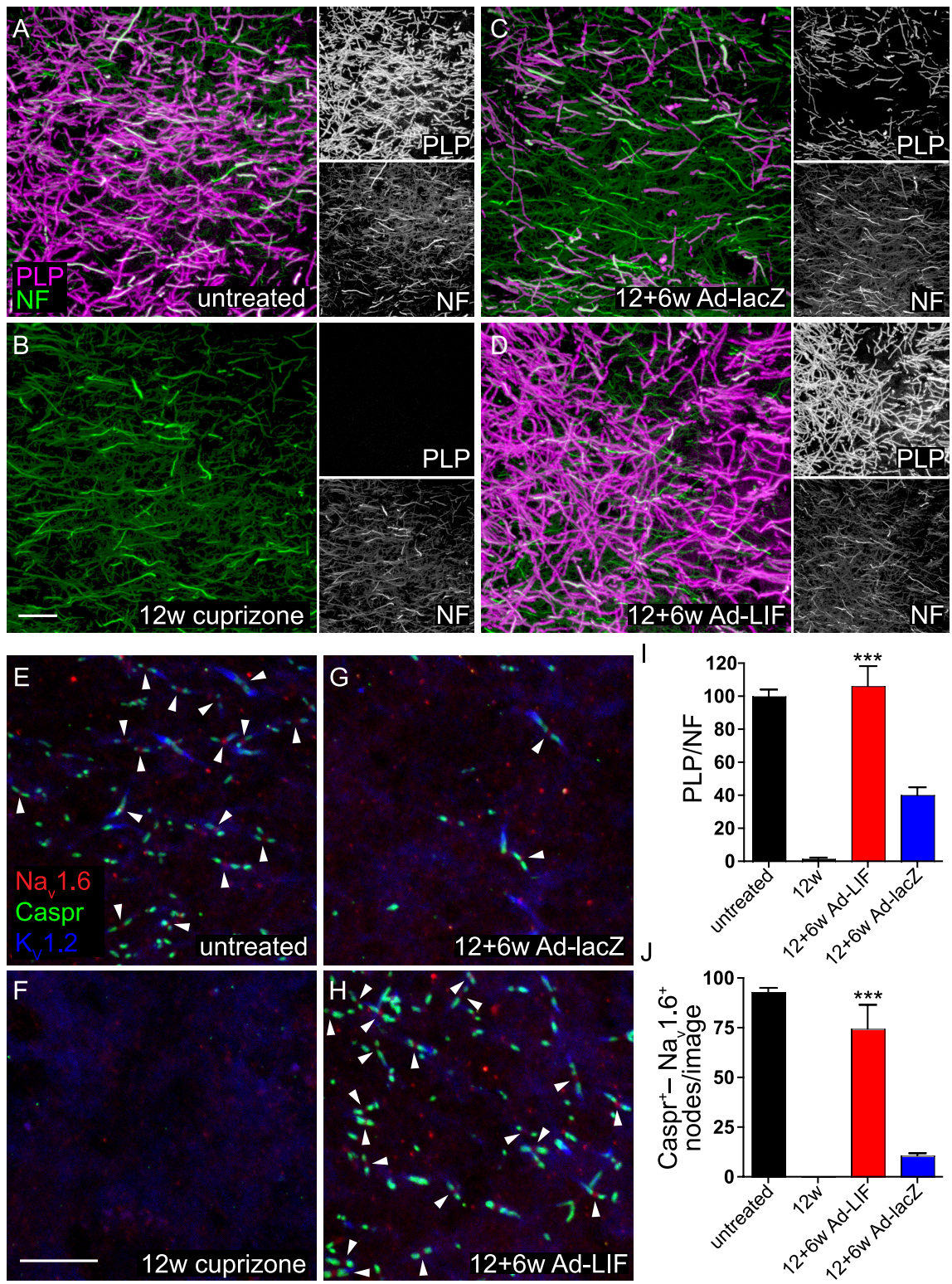

Figure 4. Myelin protein expression and node of Ranvier formation is enhanced by Ad-LIF treatment. Myelin protein (PLP) and nodes of Ranvier were assessed in the CA3 stratum radiatum of the hippocampus. $\boldsymbol{A}-\boldsymbol{D}, \boldsymbol{I}, \mathrm{Ad}$-LIF restores expression of the compact myelin protein PLP after chronic demyelination. $\boldsymbol{A}-\boldsymbol{D}$, Confocal projection images of immunostaining for PLP (purple) and $\mathrm{NF}$ (green) are shown together and as individual monochrome images to the right of each dual color image. Compared with mice maintained on a standard diet $(\boldsymbol{A})$, PLP expression is reduced after 12 weeks of cuprizone feeding $(\boldsymbol{B})$. Recovery of PLP expression is limited 6 weeks after injection with Ad-LacZ (C) compared with mice given injections of Ad-LIF (D). I, Quantification of the ratio of the area of PLP signal above threshold over the area of NF signal above threshold. $\boldsymbol{E}-\boldsymbol{H}$, Confocal projection images show immunostaining for $\mathrm{Na}_{v} 1.6$ (red), Caspr (green), and $\mathrm{K}_{v} 1.2$ (blue). Expression/clustering of node-associated proteins is disrupted by 12 week cuprizone exposure. $\boldsymbol{E}, \boldsymbol{F}$, Compare 12 week cuprizone $(\boldsymbol{F})$ to untreated $(\boldsymbol{E}) . \boldsymbol{G}, \boldsymbol{H}, \mathrm{Ad}$-LIF treatment enhances the restoration of $\mathrm{Na}_{\mathrm{v}} 1.6$ clustering surrounded by Caspr clustering at paranodes (arrowheads) compared with Ad-LacZ treatment. $\boldsymbol{J}$, Quantification of the number of $\mathrm{Na}_{v} 1.6^{+}$nodes flanked on both sides by $\mathrm{Caspr}^{+}$paranodes. ${ }^{* * *} p<0.001$ between Ad-LIF-and Ad-LacZ-treated groups. Scale bars, $20 \mu \mathrm{m}$.

port of this later possibility, high doses of LIF are disruptive to myelination in culture, whereas lower doses enhance myelination (Ishibashi et al., 2006).

\section{LIF-stimulated OPC proliferation requires gp130 signaling within OPCs}

We next sought to determine whether the effects of exogenous LIF treatment on OPC proliferation occur through the activation of gp130 receptor signaling in these cells. STAT3 is activated
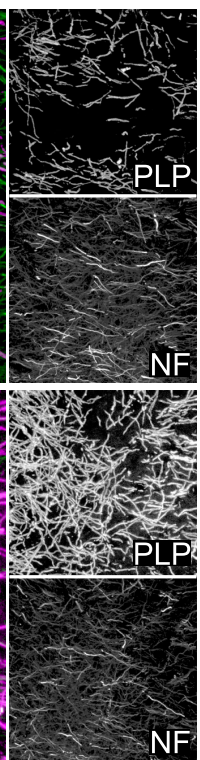

downstream of LIF/gp130 signaling, and we detect the presence of activated, phosphorylated STAT3 in multiple cell types, including astrocytes, microglia, and proliferating OPCs, responding to exogenous LIF (Fig. $1 C, D$; and data not shown). Since LIF and the related cytokine CNTF enhance the proliferation rate of purified OPCs in the presence of PDGF (Barres et al., 1996), the in vivo effect of LIF on OPC proliferation may, likewise, occur through direct stimulation of these cells. Alternatively, LIF also has effects on other cell types, including astrocytes, microglia, and endothelial cells, all of which can produce factors that stimulate OPC proliferation (Arnett et al., 2001; Albrecht et al., 2003, 2007; Arai and Lo, 2009). Therefore, it is plausible that such cells indirectly mediate the effect of LIF on OPC proliferation. To distinguish between these possible mechanisms, we asked whether OPCs continue to proliferate in response to LIF after they are rendered insensitive to direct LIF signaling. For this purpose, we conditionally inactivated the gp130 signaling subunit of the LIF receptor in OL lineage cells by crossing gp130 ${ }^{\mathrm{fl}}$ mice (Betz et al., 1998) with Ng2Cre BAC transgenic mice (Zhu et al.,

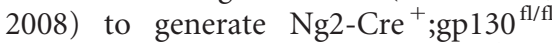
mice, hereafter referred to as gp $130^{\Delta \mathrm{NG} 2}$ mice. The gp $130^{\Delta \mathrm{NG} 2}$ and control and the gp130 ${ }^{\text {HetNG2 }}$ and Ng2-Cre ${ }^{-}$littermates were given injections of Ad-LIF and $4 \mathrm{~d}$ later were given BrdU in the drinking water $24 \mathrm{~h}$ before they were killed. We confirmed functional gp130 deletion within the OL lineage of gp $130^{\Delta \mathrm{NG} 2}$ mice by immunostaining for pSTAT3 in Olig ${ }^{+} /$ $\mathrm{CC}^{-}{ }^{-}$OPCs (Fig. 5A,B). In LIF-treated mice, pSTAT3 is detectable in $92.1 \pm 0.6 \%$ of periventricular OPCs in control mice, whereas in contrast, pSTAT3 is only detectable in $24.3 \pm 3.4 \%$ of periventricular Olig $2^{+} / \mathrm{CC} 1{ }^{-}$OPCs in gp $130^{\Delta \mathrm{NG} 2}$ mice (mean \pm SEM; $n=3-4$ per group). As we have observed in wild-type mice, LIF strongly induces OPC proliferation in control mice that retain one or both copies of functional gp130; however, in gp130 ${ }^{\Delta \mathrm{NG} 2}$ mice, LIF-enhanced OPC proliferation is severely reduced (Fig. $5 C$ ). It is likely that ablation of gp130 in OPCs completely abolishes their proliferative response to LIF given that cre-mediated recombination of gp130 floxed alleles seems to occur in $<80 \%$ of adult OPCs. As an internal control, we also assessed the LIF-induced proliferation of non-OL lineage cells. As expected, in both gp $130^{\Delta \mathrm{NG} 2}$ and control mice, LIF strongly stimulates the proliferation of Olig2-negative cells (Fig. 5D), which are mostly microglia, demonstrating that the lack of Olig $2^{+} / \mathrm{BrdU}^{+}$cells in gp130 ${ }^{\Delta \mathrm{NG} 2}$ mice is not simply an artifact arising from a reduced LIF response. 

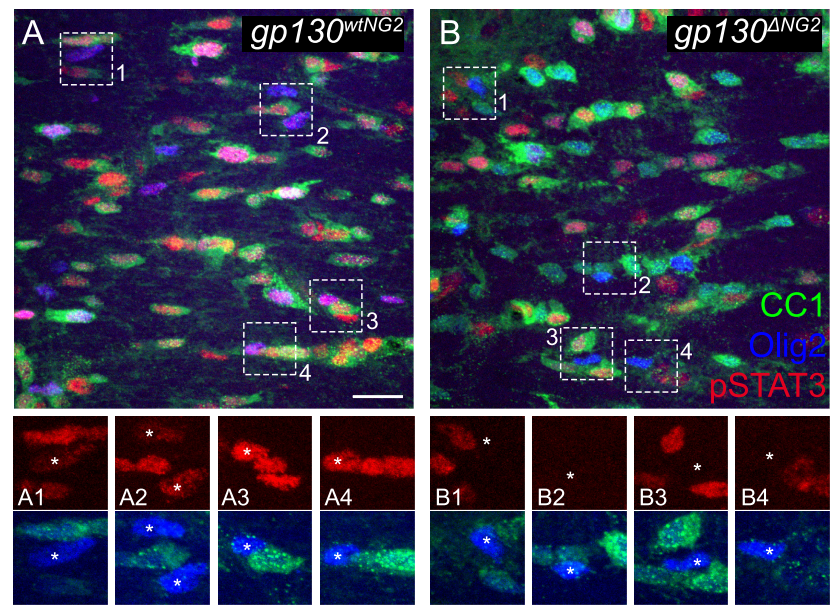

C

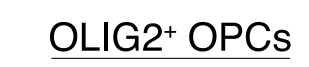

D
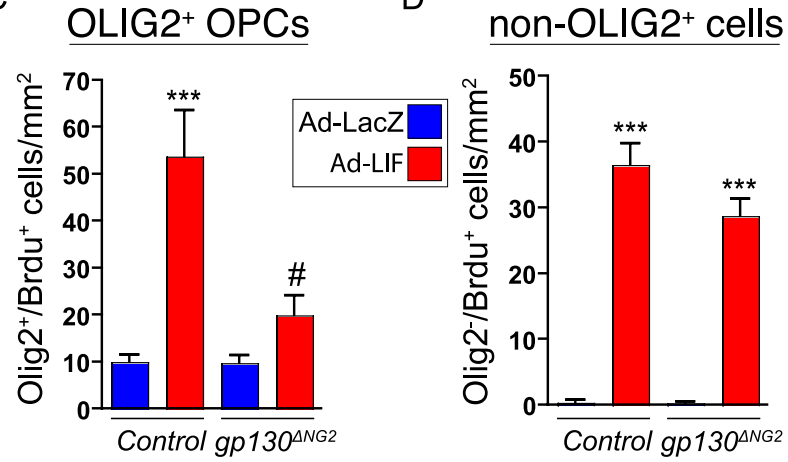

Figure 5. Stimulation of $\mathrm{OPC}$ proliferation by exogenous LIF is reduced by deletion of gp 130 in the $0 \mathrm{~L}$ lineage. Six-week-old gp $130^{\Delta \mathrm{NG} 2}\left(\mathrm{Ng2}-\mathrm{Cre}^{+} ; \mathrm{gp} 13 \mathrm{f}^{\mathrm{fl} / \mathrm{fl}}\right)$ and control, gp $130^{\text {Het NG2 }}$ $\left(\mathrm{Ng}^{2}-\mathrm{Cre}^{+} ; \mathrm{gp} 130^{\mathrm{f} / \mathrm{wt}}\right)$, and $\mathrm{Ng} 2-\mathrm{Cre}^{-}$(gp130 $0^{\mathrm{f} / \mathrm{fl}}$ or $\mathrm{gp} 130^{\mathrm{f} / \mathrm{wt}}$ ) littermates were given injections of either Ad-LIF or Ad-lacZ and 4 d later were given BrdU in their drinking water for the final $24 \mathrm{~h}$ before they were killed. $A, B$, The majority of 0 lig $2^{+} / \mathrm{CC}^{-} \mathrm{OPCs}$ in gp $130^{\Delta \mathrm{NG} 2}$ mice no longer activate STAT3 in response to LIF treatment, as demonstrated by immunostaining for pSTAT3 (red), Olig2 (blue), and CC1 (green). Numbered dashed boxes in $\boldsymbol{A}$ and $\boldsymbol{B}$ are enlarged below each image and separated into red (pSTAT3) and green/blue (CC1/0lig2) channels to demonstrate colocalization of pSTAT3 ${ }^{+}$nuclei with 0 lig2 ${ }^{+} / \mathrm{CC}^{-}{ }^{-}$cells marked with asterisks. C, D, Olig2 ${ }^{+}$and Brdu ${ }^{+}$cells were counted in confocal images taken of the fimbria. $C$, The graph shows the number of Olig2 ${ }^{+} / B r d U^{+}$cells $/ \mathrm{mm}^{2}$. D, The graph shows the number of Olig2-negative, BrdU ${ }^{+}$cells $/ \mathrm{mm}^{2}$. The gp $130^{\mathrm{HetNG2}}$ and $\mathrm{Ng2}-\mathrm{Cre}^{-}$mice were combined in the Ad-LIF and Ad-lacZ control groups. $n=3-6$ mice per group. $\operatorname{In} C,{ }^{* * *} p<0.001$ compared with all other groups; ${ }^{*}$ Not significantly different from Ad-LacZ-treated groups. In $\boldsymbol{D}^{* * *} p<$ 0.001 between Ad-LIF and Ad-LacZ, regardless of genotype. Scale bar, $20 \mu \mathrm{m}$.

One additional caveat to using the Ng2-Cre BAC transgenic line to ablate gp130 is that gp130 ablation would also be expected to occur in OLs, which are derived from $\mathrm{Ng} 2^{+}$cells, as well as pericytes, which can express Ng2 (Ozerdem et al., 2001). However, by using the ROSA-YFP reporter line to assess the efficiency of Cre recombination from the $\mathrm{Ng} 2$-Cre line, we find Cremediated YFP expression in only $60.4 \pm 4.1 \%$ of CC $1{ }^{+}$OLs in the dorsal forebrain and infrequently in pericytes (data not shown), whereas YFP expression is detected in $88.3 \pm 5.3 \%$ of adult $\mathrm{Ng} 2{ }^{+} \mathrm{OPCs}$ (mean $\pm \mathrm{SEM} ; n=2$ ). Consistent with this, we observe LIF-induced pSTAT3 activation in many CC1 ${ }^{+} \mathrm{OLs}$ in gp130 ${ }^{\Delta \mathrm{NG} 2}$ mice (Fig. $5 B$ ). In light of these findings, we think it is unlikely that inactivation of gp130 from only a subset of mature OLs or pericytes is responsible for the near-complete lack of LIFinduced proliferation of OPCs in gp $130^{\Delta \mathrm{NG} 2}$ mice.

\section{Discussion}

Here we report that exogenous LIF delivery to the adult mouse CNS can be used to enhance the endogenous progenitor cell re- sponse and promote remyelination after cuprizone-induced demyelination. A key finding of this study is that exogenous LIF stimulates OPC proliferation, as demonstrated by an increase in BrdU incorporation in OPCs. This increase in proliferation is observed both early (2-5 d) as well as 3 weeks after Ad-LIF delivery, indicating that the continuous release of LIF from adenovirus-infected ependymal cells results in a sustained response that expands the OPC population. Because LIF and other gp130 cytokines enhance the survival of OL lineage cells in vivo and in vitro, it is possible that the pro-survival effect of LIF also contributes to the expansion of the OPC pool and subsequently increased OL generation. Indeed, sustained LIF exposure seems to support the survival of supraphysiological numbers of Olig2 ${ }^{+}$, OL lineage cells (Fig. $1 G, H$ ), most notably in regions adjacent to the ventricles where LIF levels are presumably the highest. Therefore, LIF not only stimulates OPC proliferation but may further support the expansion of OL lineage cells by enhancing their survival.

The finding that LIF expands the population of prelabeled $\mathrm{YFP}^{+}$OPCs in PDGFRa-CreER;ROSA-YFP mice also strongly suggests that LIF mediates this expansion by acting primarily upon pre-existing, parenchymal OPCs rather than by enhancing the production of new OPCs from SVZ progenitors, since fate tracing in these mice specifically labels OPCs and their progeny but does not label SVZ NSCs (Rivers et al., 2008). This conclusion is also supported by our previous experiment showing that these proliferating parenchymal progenitors were not labeled by the injection of a GFP-encoding retrovirus into the SVZ (Bauer and Patterson, 2006). Given that OPCs are very abundant and widely disseminated throughout the CNS, they represent an ideal target population for therapeutic approaches aimed at promoting the generation of new OLs.

Our finding that ablation of gp130 in OL lineage cells dramatically reduces their proliferative response to LIF suggests that LIF stimulates their proliferation directly. Alternatively, LIF might stimulate OPCs by inducing the expression of additional gp130 cytokines. Regardless, we demonstrate that activation of gp130 signaling within OPCs is necessary for their proliferative response to exogenous LIF. Thus, gp130 cytokine-based strategies aimed at promoting myelin repair would require direct action on OPCs. Whether this can be achieved without direct delivery to the CNS requires further study. LIF can cross the blood-brain barrier through a saturable transport mechanism (Pan et al., 2000) that is enhanced by neuroinflammation (Pan et al., 2008), raising the possibility that systemically delivered LIF may be sufficient to mediate the effects on OPCs, especially at sites of inflammatory demyelination. Indeed, Butzkueven et al. (2002) were able to detect systemically injected LIF in the CNS of mice with experimental autoimmune encephalomyelitis (EAE) but not in nonEAE controls. Notably, daily systemic LIF administration did not increase the number of $\mathrm{Ng} 2{ }^{+}$OPCs in the CC after 4 weeks of cuprizone (Marriott et al., 2008), a finding that might be explained by the lack of a direct effect of systemically delivered LIF on OPCs, or by the dramatic, spontaneous increase in OPCs that is present after 4 weeks of cuprizone treatment, which may have masked an effect of LIF on OPC expansion.

Interestingly, inactivation of gp130 in the OL lineage does not affect the basal rate of OPC proliferation in control mice, suggesting that endogenous gp130 cytokine signaling does not contribute substantially to the rate of cycling of these cells under normal physiological conditions. Likewise, neither gp $130^{\Delta \mathrm{NG} 2}$ mice nor Nes-Cre ${ }^{+}$;gp130 ${ }^{\mathrm{fl} / \mathrm{fl}}$ mice, in which gp130 signaling is ablated embryonically in nearly all neural cells, has an obvious postnatal 
hypomyelination phenotype (B. E. Deverman, unpublished data). These findings imply that the loss of gp130 signaling, either specifically in OL lineage cells or in all neural cells, does not have significant consequences for developmental myelination. Given that both LIF and CNTF knock-outs have delayed OL generation in the optic nerve (Barres et al., 1996; Ishibashi et al., 2009), the loss of these cytokines may affect the timing of OL development indirectly. Whether endogenous LIF and/or other gp130 cytokines contribute to the enhancement of OPC proliferation that occurs in response to pathological demyelination is not clear. In support of this possibility, compared with wild-type mice, OPC proliferation is reduced in $\mathrm{Cntf}^{-/-}$mice late during the course of EAE (Linker et al., 2002). In contrast, the spontaneous expansion of OPCs that occurs by 4 weeks of cuprizone treatment is not influenced by the loss of LIF (Marriott et al., 2008).

Our finding that sustained exogenous LIF expression enhances both OPC proliferation and the generation of myelinating OLs is consistent with in vitro studies but is surprising when considered in the context of studies of other factors such as PDGF and FGF2, which enhance OPC proliferation at the expense of differentiation (Goddard et al., 2001; Armstrong et al., 2002, 2006; Woodruff et al., 2004). How LIF stimulates both OPC proliferation and OL differentiation is unclear. Since LIF, like CNTF, is not mitogenic for OPCs per se, but only expands the number of OPCs in the presence of PDGF (Barres et al., 1996), one hypothesis is that LIF-induced gp130 signaling may "activate" OPCs, thereby enhancing both their response to mitogens when present and to differentiation signals, such as those from demyelinated axons, when mitogens become limiting. Alternatively, LIF may promote OL differentiation indirectly by increasing the density of OPCs, which is known to promote their differentiation, at least when seeded on dorsal root ganglion neurons in culture (Rosenberg et al., 2008), or through an intrinsic timer mechanism that may limit the number of OPC divisions that can occur before the OPCs differentiate (Temple and Raff, 1986; Dugas et al., 2007). Regardless of the mechanism, we demonstrate that exogenous LIF delivery can be used to stimulate the otherwise essentially dormant OPC population to proliferate and generate new OLs that contribute to remyelination. Importantly, these beneficial effects of LIF on OL generation and remyelination cannot simply be attributed to the well described, pro-survival action of LIF on OLs since we delivered LIF to cuprizone-treated mice at a time when mature OLs are severely depleted.

The need for remyelination-enhancing therapeutics is great. Significant progress toward developing such therapies has been made by injecting exogenous progenitors, from a variety of sources that are capable of generating myelinating OLs. Progenitor transplantation seems especially promising for the treatment of the congenital hypomyelinating diseases (Windrem et al., 2008) and localized traumatic injury (Cao et al., 2005; Keirstead et al., 2005; Lowry et al., 2008), but its efficacy for inducing remyelination in adult demyelinating disorders with disseminated lesions such as MS is less certain. For these disorders, enhancing repair by stimulating OL generation from endogenous progenitor cells is an attractive option. However, progress demonstrating the efficacy of targeting endogenous OPCs and NSCs with factors to promote remyelination has been slow, with only a few factors showing therapeutic promise (Warrington et al., 2007; Harsan et al., 2008). This is attributable only in part to our incomplete understanding of the factors that influence OL lineage cells and remyelination in vivo. Progress has also been hindered by challenges associated with available animal models, most of which are poorly suited for demonstrating the efficacy of, and mechanism behind, any potential remyelination-promoting agents. This is primarily because of the relative efficiency of remyelination in rodents. Indeed, even after a 12 week course of cuprizone treatment, which has been reported to induce a chronic state of demyelination, we observe significant spontaneous remyelination in the medial CC, which masks any increase in remyelination that may occur in response to Ad-LIF treatment. We therefore focused our study on the hippocampus, where the spontaneous remyelination of axons within several layers is incomplete.

In MS, the widespread incidence of GM demyelination (Brownell and Hughes, 1962; Kidd et al., 1999; Bø et al., 2003; Geurts et al., 2005) and abnormalities (Rovaris et al., 2000; Ge et al., 2002; Vrenken et al., 2006) is now broadly appreciated, and GM changes correlate with the cognitive impairment that is common in MS patients (Rovaris et al., 2000; Vrenken et al., 2006; Amato et al., 2007). GM lesions are present throughout the cortex and hippocampus (Pirko et al., 2007; Geurts et al., 2008). Indeed, demyelinated hippocampal lesions were found in 15 of 19 MS cases (Geurts et al., 2007), and hippocampal lesions were seen in 14 of 16 randomly selected, relapse-remitting (RR) and secondary progressive (SP) patients (Roosendaal et al., 2008). In addition, hippocampal atrophy that exceeds global brain atrophy was observed in RR and SP patients, and this atrophy correlated with declining performance on a word-list learning task (Sicotte et al., 2008). Thus, cuprizone-induced demyelination of the hippocampus is an attractive model of GM demyelination and remyelination, which has not been well characterized in other animal models.

In summary, we find that exogenous delivery of the neuropoietic cytokine LIF to the CNS stimulates the proliferation of parenchymal OPCs. LIF-induced OPC proliferation is dramatically reduced when gp130 is ablated from the OL lineage, suggesting that their proliferation requires LIF-induced gp130 signaling in these cells. Importantly, the effect of LIF on OPC proliferation can be harnessed to restore the number of mature OLs, enhance myelin protein expression, and reform nodes of Ranvier in the chronically demyelinated hippocampus of cuprizone-treated mice. Thus, LIF has repair-promoting activities that could be beneficial for disorders and injuries in which demyelination contributes to ongoing disability. Together with previous studies showing that LIF can ameliorate EAE (Butzkueven et al., 2002; Slaets et al., 2010; Cao et al., 2011) and improve OL survival and motor symptoms after spinal cord injury (Zang and Cheema, 2003; Kerr and Patterson, 2005), our findings should reinforce interest in the further exploration of LIF, and other gp130 cytokines, as therapeutic agents for demyelinating disorders.

\section{References}

Albrecht PJ, Murtie JC, Ness JK, Redwine JM, Enterline JR, Armstrong RC, Levison SW (2003) Astrocytes produce CNTF during the remyelination phase of viral-induced spinal cord demyelination to stimulate FGF-2 production. Neurobiol Dis 13:89-101.

Albrecht PJ, Enterline JC, Cromer J, Levison SW (2007) CNTF-activated astrocytes release a soluble trophic activity for oligodendrocyte progenitors. Neurochem Res 32:263-271.

Amato MP, Portaccio E, Goretti B, Zipoli V, Battaglini M, Bartolozzi ML, Stromillo ML, Guidi L, Siracusa G, Sorbi S, Federico A, De Stefano N (2007) Association of neocortical volume changes with cognitive deterioration in relapsing-remitting multiple sclerosis. Arch Neurol 64:1157-1161.

Arai K, Lo EH (2009) An oligovascular niche: cerebral endothelial cells promote the survival and proliferation of oligodendrocyte precursor cells. J Neurosci 29:4351-4355.

Armstrong RC, Le TQ, Frost EE, Borke RC, Vana AC (2002) Absence of 
fibroblast growth factor 2 promotes oligodendroglial repopulation of demyelinated white matter. J Neurosci 22:8574-8585.

Armstrong RC, Le TQ, Flint NC, Vana AC, Zhou YX (2006) Endogenous cell repair of chronic demyelination. J Neuropathol Exp Neurol 65:245-256.

Arnett HA, Mason J, Marino M, Suzuki K, Matsushima GK, Ting JP (2001) TNF alpha promotes proliferation of oligodendrocyte progenitors and remyelination. Nat Neurosci 4:1116-1122.

Baba H, Akita H, Ishibashi T, Inoue Y, Nakahira K, Ikenaka K (1999) Completion of myelin compaction, but not the attachment of oligodendroglial processes triggers $\mathrm{K}(+)$ channel clustering. J Neurosci Res 58:752-764.

Barres BA, Burne JF, Holtmann B, Thoenen H, Sendtner M, Raff MC (1996) Ciliary neurotrophic factor enhances the rate of oligodendrocyte generation. Mol Cell Neurosci 8:146-156.

Bauer S, Patterson PH (2006) Leukemia inhibitory factor promotes neural stem cell self-renewal in the adult brain. J Neurosci 26:12089-12099.

Betz UA, Bloch W, van den Broek M, Yoshida K, Taga T, Kishimoto T, Addicks K, Rajewsky K, Müller W (1998) Postnatally induced inactivation of gp130 in mice results in neurological, cardiac, hematopoietic, immunological, hepatic, and pulmonary defects. J Exp Med 188:1955-1965.

Bø L, Vedeler CA, Nyland HI, Trapp BD, Mork SJ (2003) Subpial demyelination in the cerebral cortex of multiple sclerosis patients. J Neuropathol Exp Neurol 62:723-732.

Brownell B, Hughes JT (1962) The distribution of plaques in the cerebrum in multiple sclerosis. J Neurol Neurosurg Psychiatry 25:315-320.

Butzkueven H, Zhang JG, Soilu-Hanninen M, Hochrein H, Chionh F, Shipham KA, Emery B, Turnley AM, Petratos S, Ernst M, Bartlett PF, Kilpatrick TJ (2002) LIF receptor signaling limits immune-mediated demyelination by enhancing oligodendrocyte survival. Nat Med 8:613-619.

Cai J, Chen Y, Cai WH, Hurlock EC, Wu H, Kernie SG, Parada LF, Lu QR (2007) A crucial role for Olig2 in white matter astrocyte development. Development 134:1887-1899.

Cao Q, Xu XM, Devries WH, Enzmann GU, Ping P, Tsoulfas P, Wood PM, Bunge MB, Whittemore SR (2005) Functional recovery in traumatic spinal cord injury after transplantation of multineurotrophin-expressing glial-restricted precursor cells. J Neurosci 25:6947-6957.

Cao W, Yang Y, Wang Z, Liu A, Fang L, Wu F, Hong J, Shi Y, Leung S, Dong C, Zhang JZ (2011) Leukemia inhibitory factor inhibits T helper 17 cell differentiation and confers treatment effects of neural progenitor cell therapy in autoimmune disease. Immunity 35:273-284.

Doetsch F, Caillé I, Lim DA, García-Verdugo JM, Alvarez-Buylla A (1999) Subventricular zone astrocytes are neural stem cells in the adult mammalian brain. Cell 97:703-716.

Dugas JC, Ibrahim A, Barres BA (2007) A crucial role for p57(Kip2) in the intracellular timer that controls oligodendrocyte differentiation. J Neurosci 27:6185-6196.

Ge Y, Grossman RI, Udupa JK, Babb JS, Mannon LJ, McGowan JC (2002) Magnetization transfer ratio histogram analysis of normal-appearing gray matter and normal-appearing white matter in multiple sclerosis. J Comput Assist Tomogr 26:62-68.

Geurts JJ, Bö L, Pouwels PJ, Castelijns JA, Polman CH, Barkhof F (2005) Cortical lesions in multiple sclerosis: combined postmortem MR imaging and histopathology. AJNR Am J Neuroradiol 26:572-577.

Geurts JJ, Bö L, Roosendaal SD, Hazes T, Daniëls R, Barkhof F, Witter MP, Huitinga I, van der Valk P (2007) Extensive hippocampal demyelination in multiple sclerosis. J Neuropathol Exp Neurol 66:819-827.

Geurts JJ, Blezer EL, Vrenken H, van der Toorn A, Castelijns JA, Polman CH, Pouwels PJ, Bö L, Barkhof F (2008) Does high-field MR imaging improve cortical lesion detection in multiple sclerosis? J Neurol 255:183-191.

Goddard DR, Berry M, Kirvell SL, Butt AM (2001) Fibroblast growth factor- 2 inhibits myelin production by oligodendrocytes in vivo. Mol Cell Neurosci 18:557-569.

Hachem S, Aguirre A, Vives V, Marks A, Gallo V, Legraverend C (2005) Spatial and temporal expression of S100B in cells of oligodendrocyte lineage. Glia 51:81-97.

Haroon F, Drögemuller K, Händel U, Brunn A, Reinhold D, Nishanth G, Mueller W, Trautwein C, Ernst M, Deckert M, Schlüter D (2011) Gp130-dependent astrocytic survival is critical for the control of autoimmune central nervous system inflammation. J Immunol 186:6521-6531.
Harsan L, Steibel J, Zaremba A, Agin A, Sapin R, Poulet P, Guignard B, Parizel N, Grucker D, Boehm N, Miller RH, Ghandour MS (2008) Recovery from chronic demyelination by thyroid hormone therapy: myelinogenesis induction and assessment by diffusion tensor magnetic resonance imaging. J Neurosci 28:14189-14201.

Hendriks JJ, Slaets H, Carmans S, de Vries HE, Dijkstra CD, Stinissen P, Hellings N (2008) Leukemia inhibitory factor modulates production of inflammatory mediators and myelin phagocytosis by macrophages. J Neuroimmunol 204:52-57.

Ishibashi T, Dakin KA, Stevens B, Lee PR, Kozlov SV, Stewart CL, Fields RD (2006) Astrocytes promote myelination in response to electrical impulses. Neuron 49:823-832.

Ishibashi T, Lee PR, Baba H, Fields RD (2009) Leukemia inhibitory factor regulates the timing of oligodendrocyte development and myelination in the postnatal optic nerve. J Neurosci Res 87:3343-3355.

Keirstead HS, Nistor G, Bernal G, Totoiu M, Cloutier F, Sharp K, Steward O (2005) Human embryonic stem cell-derived oligodendrocyte progenitor cell transplants remyelinate and restore locomotion after spinal cord injury. J Neurosci 25:4694-4705.

Kerr BJ, Patterson PH (2004) Potent pro-inflammatory actions of leukemia inhibitory factor in the spinal cord of the adult mouse. Exp Neurol 188:391-407.

Kerr BJ, Patterson PH (2005) Leukemia inhibitory factor promotes oligodendrocyte survival after spinal cord injury. Glia 51:73-79.

Kidd D, Barkhof F, McConnell R, Algra PR, Allen IV, Revesz T (1999) Cortical lesions in multiple sclerosis. Brain 122:17-26.

Leibinger M, Müller A, Andreadaki A, Hauk TG, Kirsch M, Fischer D (2009) Neuroprotective and axon growth-promoting effects following inflammatory stimulation on mature retinal ganglion cells in mice depend on ciliary neurotrophic factor and leukemia inhibitory factor. J Neurosci 29:14334-14341.

Linker RA, Mäurer M, Gaupp S, Martini R, Holtmann B, Giess R, Rieckmann P, Lassmann H, Toyka KV, Sendtner M, Gold R (2002) CNTF is a major protective factor in demyelinating CNS disease: a neurotrophic cytokine as modulator in neuroinflammation. Nat Med 8:620-624.

Louis JC, Magal E, Takayama S, Varon S (1993) CNTF protection of oligodendrocytes against natural and tumor necrosis factor-induced death. Science 259:689-692.

Lowry N, Goderie SK, Adamo M, Lederman P, Charniga C, Gill J, Silver J, Temple S (2008) Multipotent embryonic spinal cord stem cells expanded by endothelial factors and Shh/RA promote functional recovery after spinal cord injury. Exp Neurol 209:510-522.

Marriott MP, Emery B, Cate HS, Binder MD, Kemper D, Wu Q, Kolbe S, Gordon IR, Wang H, Egan G, Murray S, Butzkueven H, Kilpatrick T] (2008) Leukemia inhibitory factor signaling modulates both central nervous system demyelination and myelin repair. Glia 56:686-698.

Mason JL, Suzuki K, Chaplin DD, Matsushima GK (2001) Interleukin1beta promotes repair of the CNS. J Neurosci 21:7046-7052.

Mason JL, Toews A, Hostettler JD, Morell P, Suzuki K, Goldman JE, Matsushima GK (2004) Oligodendrocytes and progenitors become progressively depleted within chronically demyelinated lesions. Am J Pathol 164:1673-1682.

Mayer M, Bhakoo K, Noble M (1994) Ciliary neurotrophic factor and leukemia inhibitory factor promote the generation, maturation and survival of oligodendrocytes in vitro. Development 120:143-153.

Menn B, Garcia-Verdugo JM, Yaschine C, Gonzalez-Perez O, Rowitch D, Alvarez-Buylla A (2006) Origin of oligodendrocytes in the subventricular zone of the adult brain. J Neurosci 26:7907-7918.

Nishiyama A (2007) Polydendrocytes: NG2 cells with many roles in development and repair of the CNS. Neuroscientist 13:62-76.

Ozerdem U, Grako KA, Dahlin-Huppe K, Monosov E, Stallcup WB (2001) NG2 proteoglycan is expressed exclusively by mural cells during vascular morphogenesis. Dev Dyn 222:218-227.

Pan W, Kastin AJ, Brennan JM (2000) Saturable entry of leukemia inhibitory factor from blood to the central nervous system. J Neuroimmunol 106:172-180.

Pan W, Yu C, Hsuchou H, Zhang Y, Kastin A (2008) Neuroinflammation facilitates LIF entry into brain: role of TNF. Am J Physiol Cell Physiol.

Pirko I, Lucchinetti CF, Sriram S, Bakshi R (2007) Gray matter involvement in multiple sclerosis. Neurology 68:634-642.

Rickmann M (1995) S100 immunoreactivity in a subpopulation of oligodendrocytes and Ranvier's nodes of adult rat brain 186:13-16. 
Rivers LE, Young KM, Rizzi M, Jamen F, Psachoulia K, Wade A, Kessaris N, Richardson WD (2008) PDGFRA/NG2 glia generate myelinating oligodendrocytes and piriform projection neurons in adult mice. Nat Neurosci 11:1392-1401.

Roosendaal SD, Moraal B, Vrenken H, Castelijns JA, Pouwels PJ, Barkhof F, Geurts JJ (2008) In vivo MR imaging of hippocampal lesions in multiple sclerosis. J Magn Reson Imaging 27:726-731.

Rosenberg SS, Kelland EE, Tokar E, De la Torre AR, Chan JR (2008) The geometric and spatial constraints of the microenvironment induce oligodendrocyte differentiation. Proc Natl Acad Sci U S A 105:14662-14667.

Rovaris M, Filippi M, Minicucci L, Iannucci G, Santuccio G, Possa F, Comi G (2000) Cortical/subcortical disease burden and cognitive impairment in patients with multiple sclerosis. AJNR Am J Neuroradiol 21:402-408.

Sicotte NL, Kern KC, Giesser BS, Arshanapalli A, Schultz A, Montag M, Wang H, Bookheimer SY (2008) Regional hippocampal atrophy in multiple sclerosis. Brain 131:1134-1141.

Slaets H, Hendriks JJ, Van den Haute C, Coun F, Baekelandt V, Stinissen P, Hellings N (2010) CNS-targeted LIF expression improves therapeutic efficacy and limits autoimmune-mediated demyelination in a model of multiple sclerosis. Mol Ther 18:684-691.

Srinivas S, Watanabe T, Lin CS, William CM, Tanabe Y, Jessell TM, Costantini F (2001) Cre reporter strains produced by targeted insertion of EYFP and ECFP into the ROSA26 locus. BMC Dev Biol 1:4.

Sugiura S, Lahav R, Han J, Kou SY, Banner LR, de Pablo F, Patterson PH (2000) Leukaemia inhibitory factor is required for normal inflammatory responses to injury in the peripheral and central nervous systems in vivo and is chemotactic for macrophages in vitro. Eur J Neurosci 12:457-466.

Tatsumi K, Takebayashi H, Manabe T, Tanaka KF, Makinodan M, Yamauchi T, Makinodan E, Matsuyoshi H, Okuda H, Ikenaka K, Wanaka A (2008) Genetic fate mapping of Olig2 progenitors in the injured adult cerebral cortex reveals preferential differentiation into astrocytes. J Neurosci Res 86:3494-3502.
Temple S, Raff MC (1986) Clonal analysis of oligodendrocyte development in culture: evidence for a developmental clock that counts cell divisions. Cell 44:773-779.

Vrenken H, Pouwels PJ, Geurts JJ, Knol DL, Polman CH, Barkhof F, Castelijns JA (2006) Altered diffusion tensor in multiple sclerosis normalappearing brain tissue: cortical diffusion changes seem related to clinical deterioration. J Magn Reson Imaging 23:628-636.

Warrington AE, Bieber AJ, Ciric B, Pease LR, Van Keulen V, Rodriguez M (2007) A recombinant human IgM promotes myelin repair after a single, very low dose. J Neurosci Res 85:967-976.

Windrem MS, Schanz SJ, Guo M, Tian GF, Washco V, Stanwood N, Rasband M, Roy NS, Nedergaard M, Havton LA, Wang S, Goldman SA (2008) Neonatal chimerization with human glial progenitor cells can both remyelinate and rescue the otherwise lethally hypomyelinated shiverer mouse. Cell Stem Cell 2:553-565.

Woodruff RH, Fruttiger M, Richardson WD, Franklin RJ (2004) Plateletderived growth factor regulates oligodendrocyte progenitor numbers in adult CNS and their response following CNS demyelination. Mol Cell Neurosci 25:252-262.

Zang DW, Cheema SS (2003) Leukemia inhibitory factor promotes recovery of locomotor function following spinal cord injury in the mouse. J Neurotrauma 20:1215-1222.

Zhang Y, Taveggia C, Melendez-Vasquez C, Einheber S, Raine CS, Salzer JL, Brosnan CF, John GR (2006) Interleukin-11 potentiates oligodendrocyte survival and maturation, and myelin formation. J Neurosci 26:12174-12185.

Zhu M, Oishi K, Lee SC, Patterson PH (2001) Studies using leukemia inhibitory factor (LIF) knockout mice and a LIF adenoviral vector demonstrate a key anti-inflammatory role for this cytokine in cutaneous inflammation. J Immunol 166:2049-2054.

Zhu X, Bergles DE, Nishiyama A (2008) NG2 cells generate both oligodendrocytes and gray matter astrocytes. Development 135:145-157. 